\title{
Microwave Reactors: A Brief Review on Its Fundamental Aspects and Applications
}

\author{
Kalyan Kumar Rana ${ }^{*}$, Suparna Rana ${ }^{2}$ \\ ${ }^{1}$ Department of Chemistry, Gushkara Mahavidyalaya, Gushkara, Burdwan, WB, India \\ ${ }^{2}$ Department of Applied Science, Haldia Institute of Technology, Haldia, WB, India \\ Email: kalyankrana@yahoo.co.in, ranamandal@yahoo.co.in
}

Received 1 July 2014; revised 2 August 2014; accepted 10 September 2014

Copyright (C) 2014 by authors and OALib.

This work is licensed under the Creative Commons Attribution International License (CC BY). http://creativecommons.org/licenses/by/4.0/

(c) (i) Open Access

\begin{abstract}
Improved laboratory protocols for convenient and rapid transformations are highly desired in modern synthetic chemistry. Microwave irradiated reactions have received considerable attention in recent years and it is a subject of intense discussion in the scientific community. Microwave heating is more efficient in terms of the energy used, produces higher temperature homogeneity and is considerably more rapid than conventional heating methods. This technique as an alternative to conventional energy sources for introduction of energy into reactions has become a recognized practical method in various fields of chemistry. Microwave-assisted organic synthesis (MAOS) is known for the spectacular accelerations produced in many reactions as a consequence of the increased heating rate, a phenomenon that cannot be easily reproduced by classical heating means. As a result, higher yields, milder reaction conditions and shorter reaction times can often be attained. Its specific heating method attracts extensive interest not only because of rapid volumetric heating, but also for suppressed side reactions, energy saving, decreased environmental pollutions and safe operations. In this review, we will try to represent an overview on origin and fundamental features of microwave ovens and its usefulness in MAOS.
\end{abstract}

\section{Keywords}

Microwave, Dielectric Heating, Loss Angle, Monomode, Multimode, Synthesis

Subject Areas: Green Chemistry, Material Experiment, Organic Chemistry

\section{Introduction}

The first chemists or alchemists as they may be called, transformed one body into another by means of, principally, fire. Fortunately, fire is now rarely used but it was not until Robert Wilhelm Eberhard Bunsen (1811-1899,

${ }^{*}$ Corresponding author. 
discoverer of caesium in 1860 and rubidium in 1861) invented the burner that the energy from this heat source could be applied to the reaction vessel in a focused manner. The Bunsen burner was later superseded by the heating mantle, oil bath or hot plate. Recently, a new technique has come to the forefront of chemical research, microwave dielectric heating. In a similar way to the introduction of the heating mantle, this technology will no doubt require a change in the chemist's mindset. In 1986, Gedye and Giguere reported [1] for the first time that the organic reactions could be conducted very rapidly under microwave irradiation [1] [2]. Since then, microwave has been widely used in synthetic chemistry to reduce reaction time and increase product yield [3] [4]. Particularly over the past few years there has been a dramatic uptake in the use of microwaves as an energy source to promote synthetic transformations. The production of dedicated instrumentation by the leading manufacturers has propelled what was 20 years ago a fascinating idea into a day-to-day device for synthetic chemists. Microwaveassisted organic synthesis (MAOS) is clearly a method by which a chemist can achieve target in a fraction of the time as compared to traditional conductive heating methods. Reactions times in the best cases have been reduced from days or hours to minutes.

\section{Behind the Backdrops}

It was during a radar-related research project in 1946 in USA, end stage period of World War-II, that Dr. Percy LeBaron Spencer (1894-1970, was orphaned, never finished grammar school and bagged more than 150 patents) ([5] a), a self-taught engineer with the Raytheon Corporation, noticed something abnormal. One day, while making magnetrons, then used to generate microwave radio signals for combat radars, Spencer was standing in front of an active radar set and noticed the candy bar he had kept in his pocket had melted. Spencer was not the first man to note this incident, but he was the first to examine it. He decided to test with some popcorn kernels. Along with his colleagues, Spencer watched the popcorns were cracked, popped up and splattered all over the nearby place. This way the world's first microwaved popcorns were prepared. In continuation to his innovative trial, Spencer next took an egg, put it in a kettle and placed the magnetron above the kettle. Unfortunately, one of his curious colleagues came very close to it and tried to look from above what was happening inside the kettle. Suddenly, as per modus operandi of microwave heating, the innocent egg exploded and splattered hot viscous liquid all over the colleague's stunned face. In contrast, the face of Spencer lit up with a logical scientific idea: the melted candy bar, the popcorn and now the exploding egg were all resulting from exposure to low-density microwave energy. He thought, if an egg could be cooked quickly, why not other foodstuffs? Experimentation continued and Spencer created the first true microwave oven by joining a high density electromagnetic field generator device to an enclosed metal box. Allowing controlled and safe testing, the device emitted microwaves into the metal box without any escape. He then tried to monitor temperatures and observed effects with various foodstuffs in the box. In 1947 Raytheon produced the first commercial microwave oven which was around 6 feet tall, weighed about 750 lbs and cost between $\$ 2000$ and $\$ 3000$ at that time. The first kitchen countertop, domestic oven was produced in 1967 by Amana (a division of Raytheon). It was a 100-volt microwave oven, which cost just under \$500 and was smaller, safer and more reliable than previous models. During 1970s there was an upsurge of microwave ovens elsewhere in the world. Up to the middle of 1980's microwave oven or famous electronic oven was used only for defrosting frozen food and cooking. Since 1986 [1] the microwave has become a source of heating chemical reaction, extraction etc. So, a concise account ([5] b, c) of evolution and development of microwave ovens would be as follows:

1946-Microwave radiation was discovered as a method of heating. By late 1946, the Raytheon Company had filed a patent proposing that microwaves be used to cook food. An oven that heated food using microwave energy was then placed in a Boston restaurant for testing.

1947—Raytheon built the first commercially available microwave oven, "Radarange", standing $5.5 \mathrm{ft}$ tall, weighing over 750 lbs and costing about US \$5000 ( \$53,000 in today’s dollars) each.

1952-Raytheon licensed its technology to the Tappan Stove company of Mansfield, Ohio.

1954-Raytheon introduced the first commercial microwave oven "1161 Radarange".

1955-Tappan introduced a large, 220 volt wall unit as a home microwave oven, cost was about US \$1295 ( $\sim$ 11,500 in today’s dollars) each.

1965-Raytheon acquired Amana Home Appliances, Iowa, an American brand of household appliances.

1967-Amana introduced the first popular home model, the countertop Amana Radarange, at a price of US \$495 (\$3500 in today’s dollars) each. 
1978-First microwave laboratory instrument was developed by CEM (abbreviation for Chemistry, Electronics and Mechanics as three founders were a Chemist, an Electrical engineer and a Mechanical engineer) Corporation, USA, to analyze moisture in solids.

1983-1985-Microwave radiation was used for chemical analysis.

1986-Robert Gedye of Laurentian University, Canada, George Majetich of University of Georgia, USA and Raymond Giguere of Mercer University, USA along with their co-workers published papers relating to microwave radiation in chemical synthesis.

1990 - Milestone S.r.l., Italy, made the first high pressure MW vessel (HPV 80) for performing complete digestion of difficult to digest materials like oxides, oils and pharmaceutical compounds.

1992-1996-CEM Corporation developed a more effective batch system reactor (MDS 200) and a single mode cavity system (Star 2) that were successfully used for chemical synthesis.

1997-Milestone S.r.l. and Prof. H. M. Kingston of Duquesne University culminated the landmark reference book titled "Microwave-Enhanced Chemistry-Fundamentals, Sample Preparation, and Applications", edited by H. M. Kingston and S. J. Haswell.

1990s-Microwave chemistry emerged and developed as a most promising field of study for its applications in chemical reactions.

2000 onwards-CEM, Biotage, Anton Paar, Milestone etc. marketed a number of MW reactor models of varying capacities and temperature control that broadens the applicability and prosperity of MW assisted organic synthesis.

\section{Microwave's Essential Parameters}

Microwave heating refers to the use of electromagnetic waves of certain frequencies to generate heat in the substrate [6]. Microwaves lie in the region of the electromagnetic spectrum between millimeter wave and radio wave i.e., between I.R. and radio waves. These waves are sometimes defined as waves with wavelengths (Figure 1) between $0.01 \mathrm{~m}$ to $1 \mathrm{~m}$, corresponding to the frequency of $30 \mathrm{GHz}$ (or $3 \times 10^{4} \mathrm{MHz}$ ) to $0.3 \mathrm{GHz}$ (or $3 \times 10^{2} \mathrm{MHz}$ ).

\subsection{Basic Theory of Microwave Heating}

As stated, microwave irradiation is actually an electromagnetic irradiation in the frequency range of 0.3 to 300 $\mathrm{GHz}$. All microwave ovens, be it domestic type or dedicated microwave reactors for chemical synthesis, operate at a particular frequency of $2.45 \mathrm{GHz}$ (which corresponds to a wavelength of $12.24 \mathrm{~cm}$ ) to avoid interference with telecommunication and cellular phone frequencies. An important point is that the energy of a microwave photon in this frequency region $(0.0016 \mathrm{eV})$ is lower than the energy of Brownian motion and is also too feeble to break chemical bonds. It is, therefore, clear that microwaves, by itself, cannot induce chemical reactions ([7] a-c). Energies of chemical bonds in comparison to different microwave energies (Table 1) and standard frequencies for industrial, scientific and medical use (Table 2) are summarized.

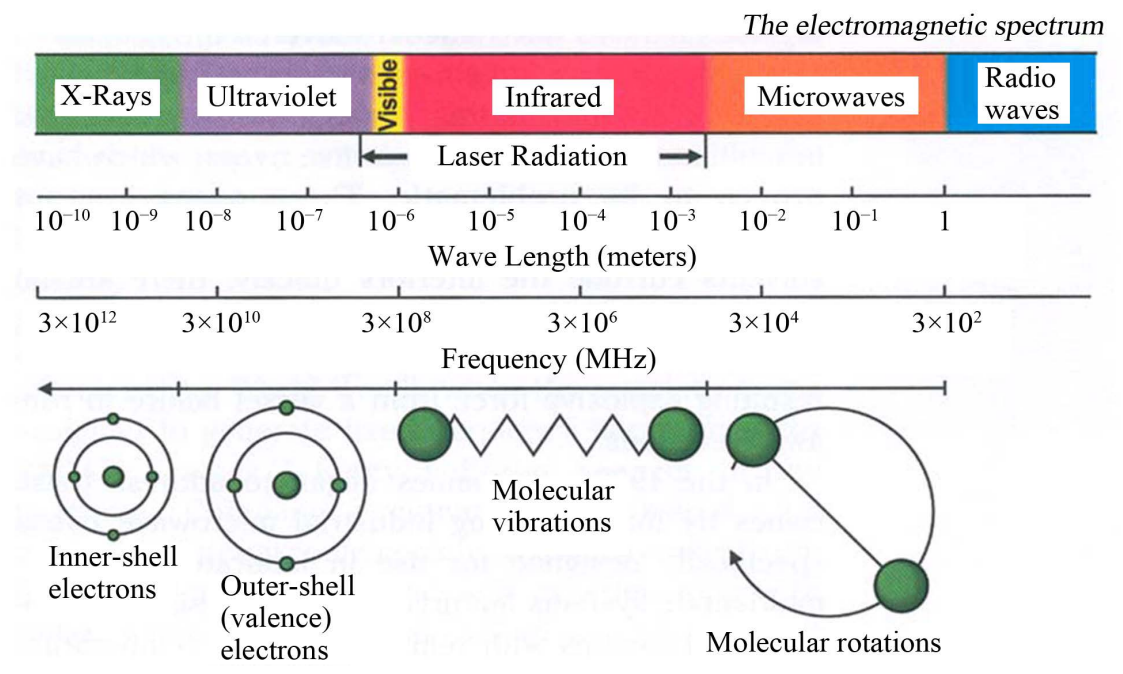

Figure 1. The electromagnetic spectrum showing characteristics of microwaves. 
Table 1. Energies of chemical bonds ${ }^{\mathrm{a}}$ in comparison to different microwave energies.

\begin{tabular}{cccc}
\hline & & Energy/eV & Energy $/ \mathrm{kJ}^{\mathrm{b}} \cdot \mathrm{mol}^{-1}$ \\
\hline 1 & CC single bond & $3.61^{\mathrm{c}}$ & 347 \\
2 & CC double bond & $6.35^{\mathrm{c}}$ & 613 \\
3 & CO single bond & $3.74^{\mathrm{c}}$ & 361 \\
4 & CC double bond & $7.71^{\mathrm{c}}$ & 744 \\
5 & CH bond & $4.28^{\mathrm{c}}$ & 413 \\
6 & OH bond & $4.80^{\mathrm{c}}$ & 463 \\
7 & hydrogen bond & $0.04-0.44^{\mathrm{d}}$ & $4-42$ \\
8 & MW 0.3 GHz & $1.2 \times 10^{-26}$ & 0.00011 \\
9 & MW 2.45 GHz & $1.0 \times 10^{-25}$ & $0.00096 \approx 1 \mathrm{~J} \cdot \mathrm{mol}^{-1}$ \\
10 & MW 30 GHz & $1.2 \times 10^{-3}$ & 0.11 \\
\hline
\end{tabular}

${ }^{\mathrm{a}}$ For more examples of strengths of chemical bonds see Ref. ([7] d); ${ }^{\mathrm{b}} 1 \mathrm{eV}=1.602177 \times 10^{-19} \mathrm{~J}$; ${ }^{\mathrm{c}}$ See Ref. ([7] e); ${ }^{\mathrm{d}}$ See Ref. ([7] f).

Table 2. In accordance with international agreements allowed frequencies for industrial, scientific and medical use (ISM-frequencies).

\begin{tabular}{cc}
\hline Frequency in MHz & Wavelength in $\mathrm{cm}$ \\
$433.92 \pm 0.2 \%$ & 69.14 \\
$915 \pm 13^{\#} 32.75$ & \\
$2450 \pm 50$ & 12.24 \\
$5800 \pm 75$ & 5.17 \\
$24125 \pm 125$ & 1.36 \\
\hline
\end{tabular}

\#Not allowed in Germany.

Microwave irradiated chemistry is based on the efficient heating of materials by "microwave dielectric heating" effects. This phenomenon is dependent on the ability of a specific material (solvent or reagent or anything else) to absorb microwave energy and convert it into heat. The electric component [8] of an electromagnetic field causes heating by two main mechanisms: dipolar polarization and ionic conduction. Irradiation of the sample at microwave frequencies results in the dipoles or ions aligning in the applied electric field. As the applied field oscillates, the dipole or ion field attempts to realign itself with the alternating electric field and in this process, energy is lost in the form of heat energy through molecular friction and dielectric loss. The amount of heat generated by this process is directly related to the ability of the matrix to align itself with the frequency of the applied field. If the dipole does not have enough time to realign with the vibrating applied electromagnetic field or reorients itself too quickly with the applied field, no heating occurs. The allocated frequency of 2.45 $\mathrm{GHz}$ used in all commercial systems lies between these two extremes and gives the molecular dipole time to align in the field, but not to follow the alternating field, in concert with its frequency, precisely ([7] b, c). The heating characteristics of a particular material (for example, a solvent) under microwave irradiation conditions are dependent on its dielectric properties. The ability of a specific substance to convert electromagnetic energy into heat at a given frequency and temperature is determined by the so-called loss factor or loss angle or loss tangent, $\tan \delta$. This loss factor is expressed as $\tan \delta=e^{\prime \prime} / e^{\prime}$, where $e^{\prime \prime}$ is the dielectric loss, which is indicative of the efficiency with which electromagnetic radiation is converted into heat and $e^{\prime}$ is the dielectric constant. A reaction medium with a high $\tan \delta$ value is more effective for fruitful absorption and consequently, for rapid heating. In other words, the more the value of loss factor or loss angle ( $\tan \delta$ ), the more will be the dielectric heating of a material under microwave irradiation. The loss angles or loss factors of some common organic solvents are summarized in Table 3. Generally, solvents are classified as high ( $\tan \delta>0.5$ ), medium ( $\tan \delta 0.1$ $0.5)$ and low microwave absorbing $(\tan \delta<0.1)$. 
Table 3. Loss factors $(\tan \delta)$ of different solvents [9] at $2.45 \mathrm{GHz}$ and $20^{\circ} \mathrm{C}$.

\begin{tabular}{cccc}
\hline Solvent & $\tan \delta$ & Solvent & $\tan \delta$ \\
\hline ethylene glycol & 1.350 & DMF & 0.161 \\
ethanol & 0.941 & 1,2-dichloroethane & 0.127 \\
DMSO & 0.825 & water & 0.123 \\
2-propanol & 0.799 & chlorobenzene & 0.101 \\
formic acid & 0.722 & chloroform & 0.091 \\
methanol & 0.659 & acetonitrile & 0.062 \\
nitrobenzene & 0.589 & ethyl acetate & 0.059 \\
1-butanol & 0.571 & acetone & 0.054 \\
2-butanol & 0.447 & tetrahydrofuran & 0.047 \\
1,2-dichlorobenzene & 0.280 & dichloromethane & 0.042 \\
N-methyl-2-pyrrolidinone (NMP) & 0.275 & toluene & 0.040 \\
acetic acid & 0.174 & hexane & 0.020 \\
\hline
\end{tabular}

Other common solvents without a permanent dipole moment such as carbon tetrachloride, benzene and dioxane are more or less microwave transparent. It is to be emphasized that a low $\tan \delta$ value does not rule out a particular solvent from being used in a microwave-heated reaction. Since either the substrates or some of the reagents/catalysts are likely to be polar, the overall dielectric properties of the reaction medium will in most cases allow sufficient heating by microwaves. Furthermore, polar additives such as ionic liquids, for example, can be added to otherwise low-absorbing reaction mixtures to increase the MW absorbance level of the medium. Of course, one must remember that the rate of temperature increase also depend upon the specific heat capacity, volume, emissivity, geometry of the molecules and the strength of the applied electromagnetic field.

\subsection{Loss Angle}

The relationship between $\tan \delta$, $e^{\prime}$ and $e^{\prime \prime}$ is purely mathematical and can be described using simple trigonometrical rules ([7] c). The dielectric loss $\left(e^{\prime \prime}\right)$ and the dielectric constant $\left(e^{\prime}\right)$ of a material are two determinants of the efficiency of heat transfer to the sample. The magnitude of the force acting between two given electric charges placed at a definite distance apart in a uniform medium is determined by a property of the medium which is known as dielectric constant. If " $e_{1}$ " and " $e_{2}$ " are the values of the two electric charges placed at a distance " $r$ " apart in a uniform medium, then the force " $F$ " acting between them is given by Coulomb's law as $F=e_{1} e_{2} / e^{\prime} r^{2}$, where $e^{\prime}=$ dielectric constant of the medium. The larger the dielectric constant, the greater the coupling with microwaves and thus, faster the rate of heating. The quotient $\left(e^{\prime \prime} / e^{\prime}\right)$ or the dissipation factor, with a high value shows ready susceptibility to microwave energy. In reality, loss angle or loss factor $(\tan \delta)$ is proportional to the polarizability and the electrical conductivity of the reaction medium which means polar and ionically conducting solvents are preferable for microwave-assisted reactions.

\subsection{Microwave Oven: The Apparatus}

Monomode and multimode are the two categories into which microwave ovens are often classified [10].

Monomode or Single-mode Microwave Oven: Monomode microwave ovens are able to create a standing wave model, which is produced by the interference of fields that have the same amplitude but different oscillating directions (Figure 2). This interface generates an arrangement of nodes where microwave energy intensity is zero and a collection of antinodes where the magnitude of microwave energy is maximum.

The main wave mechanical factor that determines the structural design of a single-mode apparatus is the distance of the sample from the magnetron. This distance should be such that the sample vessel is placed at the antinodal position of the standing electromagnetic wave pattern (Figure 3).

Among many advantages, most important advantage of single-mode apparatus is their high rate of heating. One of the drawbacks of single-mode apparatus is that, at a time, only one vessel can be irradiated. 
Multi-Mode Microwave Oven: Initial simple microwave ovens and present day household microwave ovens are of this category. Purposeful avoidance of generating a standing wave pattern inside the oven cavity is the most significant feature of a multi-mode apparatus (Figure 4). This is done so as to generate as much chaos as possible inside the cavity. The greater the chaos, the higher the dispersion of radiation which ultimately increases the area of effective heating. Thus, a multi-mode microwave heating apparatus can accommodate a number of samples simultaneously, unlike single-mode apparatus. On the basis of this characteristic, a multi-mode oven is often used for bulk heating and carrying out chemical analysis processes like ashing, extraction etc.

Improper control of heating of samples is a major limitation of multi-mode apparatus because of absence of temperature uniformity. This is largely due to the chaos of the waves that makes it practically impossible to

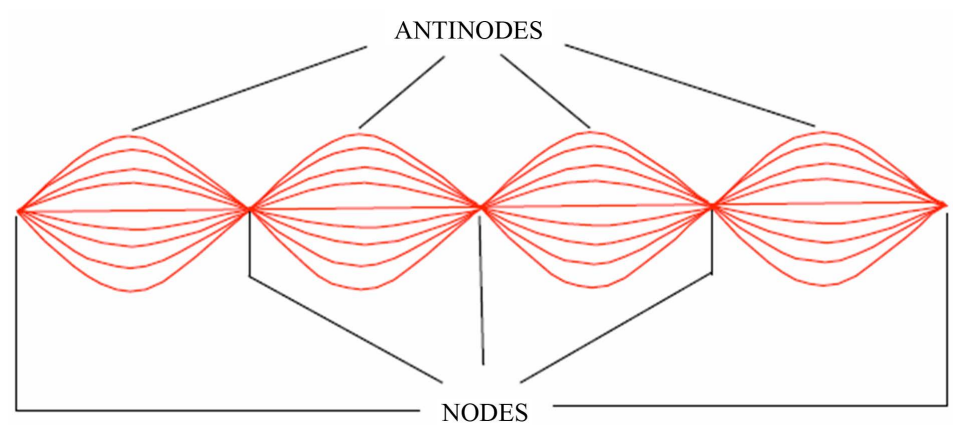

Figure 2. Standing wave pattern-Generated in monomode apparatus.

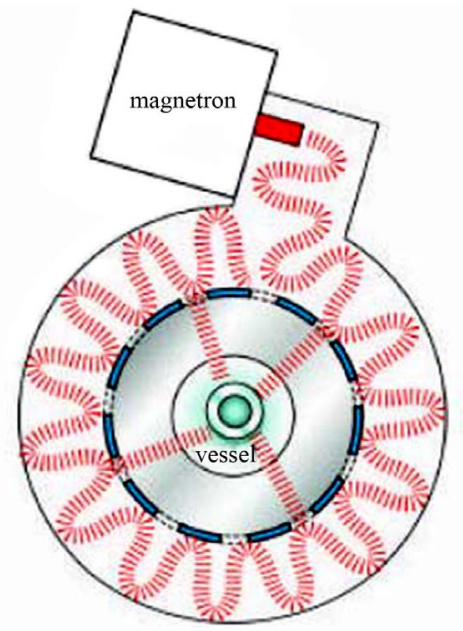

Figure 3. Mechanism of heating in monomode apparatus.

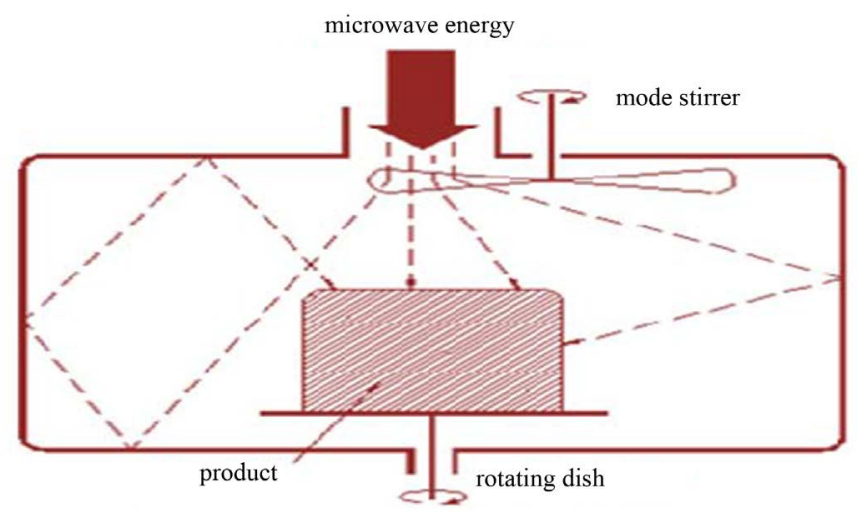

Figure 4. Design of a multi-mode heating apparatus. 
create equal heating (actually creates hot-spots and cold-spots in the material) of the samples that are kept inside the oven.

\subsection{Conventional vs Microwave Heating}

Microwave heating is different from conventional heating in many respects. Difference between these two heat sources have been discussed in a wealth of literatures [11]-[26] which are summarized below.

\begin{tabular}{|c|c|}
\hline Conventional Heating & Microwave Heating \\
\hline By thermal or electrical sources, heating takes place. & By electromagnetic waves, heating takes place. \\
\hline $\begin{array}{l}\text { Heating of reaction mixture proceeds from a surface usually } \\
\text { from the inside surface of reaction vessels. }\end{array}$ & $\begin{array}{l}\text { Heating of reaction mixture proceeds directly inside the } \\
\text { material avoiding the vessel. }\end{array}$ \\
\hline $\begin{array}{l}\text { The vessel surface is brought in physical contact with the } \\
\text { source which is at a higher temperature (e.g., burner, mantle, } \\
\text { oil bath, steam bath etc.). }\end{array}$ & $\begin{array}{l}\text { No need of physical contact of reaction vessel with the higher } \\
\text { temperature source. The reaction vessel is kept in the oven cavity } \\
\text { and microwave source or the magnetron is kept little further. }\end{array}$ \\
\hline Heating mechanism involve conduction of heat. & Heating mechanism involve dielectric polarization and ionic conduction. \\
\hline $\begin{array}{l}\text { In conventional heating, generally, the achievable highest } \\
\text { temperature is limited by boiling point of a substrate. }\end{array}$ & $\begin{array}{l}\text { In microwave, the temperature of a substrate can be raised higher than } \\
\text { its boiling point, i.e., superheating may take place. }\end{array}$ \\
\hline $\begin{array}{l}\text { In the conventional heating, all the components in a mixture } \\
\text { are heated almost equally. }\end{array}$ & $\begin{array}{l}\text { In microwave heating, specifically a particular component can be } \\
\text { heated more depending on its dielectric characteristics. }\end{array}$ \\
\hline Heating rate is less. & Heating rate is several (from 10 to 1000 in best cases) fold high. \\
\hline
\end{tabular}

\subsection{General Conditions/Guidelines for Microwave Synthesis}

Like any other scientific processes microwave irradiated reactions also have some provisions with respect to the nature of solvents, temperature, pressure etc. [27]. These are described in short as below.

\subsubsection{Solvent}

- Different solvents interact very differently with microwave, because of their diverse polar and ionic properties.

- Ethanol $(\tan \delta$ 0.941), DMF ( $\tan \delta$ 0.161) and acetonitrile ( $\tan \delta$ 0.062), are often used for microwave-assisted organic synthesis. Usually, one might need not change the solvent that is usually used under traditional conditions.

- Non-polar solvents, for example, THF ( $\tan \delta$ 0.047), toluene ( $\tan \delta 0.040)$, hexane ( $\tan \delta 0.020$ ) etc. can be heated only when other components in the reaction mixture respond to microwave energy.

- Ionic liquids are environmentally friendly and recyclable alternatives to dipolar aprotic solvents. As these are salts and readily dissolve in a wide range of organic solvents, these are better choice for MW absorption for poor absorbing reaction mixtures. The low vapor density and effective dielectric properties of ionic liquids make them highly suitable to be used as solvents or additives in microwave-assisted organic synthesis.

- Solvents with low boiling points (e.g., methanol, dichloromethane, acetone etc), have lower reaction temperatures due to the pressure build-up within the vessel. If a higher temperature is desired, it is advisable to shift to a solvent having higher boiling point with compatible $\tan \delta$ value.

\subsubsection{Volume}

- Too low volume will give an incorrect temperature measurement while a high volume does not leave sufficient head-space for pressure build-up.

\subsubsection{Pressure}

- Usually MW reactors allow reaction pressures as high as 20 bar. In dedicated MW reactors, if pressure in a vessel becomes higher, heating is automatically stopped and cooling begins. For an indication of the expected pressure of a reaction, one can use the solvent table or the vapor pressure calculator ([27] b). 


\subsubsection{Temperature}

- Optimum temperature should be as high as substrates and products allow before they start decomposing or as high as the reaction solvent allows, whichever is less.

\subsubsection{Concentration}

- The concentration depends on the type of chemistry that is performed. The maximum obtainable concentration is dependent on the properties of the substrates and reagents as well as the properties of the solvent(s) used. A unimolecular reaction is independent of concentration and can be performed in a very dilute solution. On the other hand, bi- or tri-molecular reactions are essentially concentration dependent. Higher concentration offers faster rate of reaction.

\subsubsection{Inert Atmosphere}

- Inert atmosphere, in general, is not initially employed in microwave chemistry and often not needed even if the reaction is carried out under inert media in conventional method. If needed, vials are flushed with inert gas before capping.

\subsubsection{Time}

- Generally MAOS reactions require 2 - 15 minutes of irradiation but the time required for a particular reaction would be determined by the operator himself.

\subsubsection{Reaction Optimization}

- Optimizing a microwave reaction is equivalent to optimizing a conventional synthesis, for example, if the first attempt is a failure, changing the temperature and reaction time may cause significant improvement. All remaining parameters that we usually change (i.e., concentration, solvent, reagent etc.) can be changed as and when required.

\subsection{Microwave Assisted Organic Synthesis}

In recent years microwave assisted reactions has opened the door of a new era in the field of organic synthesis [28]. The technique offers simple, clean, fast, efficient and economic protocol for the synthesis of a large number of organic molecules. Now a day's this procedure is considered as an important weapon to employ green chemistry, since this is significantly environmentally friendly. This technology is still less-used in the traditional laboratories. Conventional method of heating usually need longer time, tedious and costly apparatus setup and the excessive use of solvents/reagents that ultimately lead to environmental pollution. After initiation by Richard Gedye and his co-workers [1], chemists have successfully employed MW heating in a large number of organic reactions. A plethora of articles and reviews describing a variety of new chemistries performed with microwave irradiation have appeared [9]. Because of space constraints the major applications of microwave assisted organic syntheses are summarized in Table 4 with their corresponding references.

Let us take a look at some particular reports of MW assisted organic reactions:

1) In a report [62] of the Fischer indole synthesis, primary and secondary alcohols have been catalytically oxidized in the presence of phenylhydrazines and Lewis acids to give the corresponding indoles in a single step. Replacing aldehydes or ketones, the use of alcohols widens the scope of availability of starting materials and offers easy handling and safety.

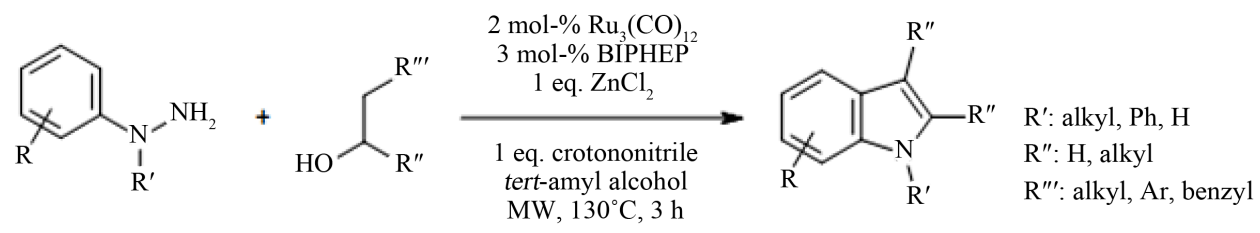

2) $N$-Sulfonyl-1,2,3-triazoles react with water in the presence of a rhodium catalyst to produce $\alpha$-amino ketones in very good yields. This conversion formally achieves 1,2-aminohydroxylation of terminal alkynes in a region selective manner in combination with a copper(I)-catalyzed 1,3-dipolar cycloaddition with $N$-sulfonyl azides [63] . 
Table 4. Few examples of microwave assisted organic synthesis.

\begin{tabular}{cccccc}
\hline Entry & Reaction & Ref. & Entry & Reaction & Ref. \\
\hline 1 & Acetylation reaction & {$[29]$} & 17 & Dehalogenation reaction & {$[45]$} \\
2 & Addition reaction & {$[30]$} & 18 & Diel's-Alder reaction & {$[46]$} \\
3 & Alkylation reaction & {$[31]$} & 19 & Dimerization reaction & {$[47]$} \\
4 & Alkynes metathesis & {$[32]$} & 20 & Elimination reaction & {$[29]$} \\
5 & Allylation reaction & {$[33]$} & 21 & Estrification/Transestrification reaction & {$[48]$} \\
6 & Amination reaction & {$[34]$} & 22 & Enantioselective reaction & {$[49]$} \\
7 & Aromatic nucleophillic substitution reaction & {$[35]$} & 23 & Halogenation reaction & {$[50]$} \\
8 & Arylation reaction & {$[36]$} & 24 & Mannich reaction & {$[51]$} \\
9 & Claisen-Smith reaction & {$[37]$} & 25 & Oxidation reaction & {$[52]$} \\
10 & Combinatorial reaction & {$[38]$} & 26 & Phosphorylation synthesis & {$[53]$} \\
11 & Condensation reaction & {$[39]$} & 27 & Polymerization reaction & {$[54]$} \\
12 & Coupling reaction & {$[40]$} & 28 & Rearrangement reaction & {$[55]$} \\
13 & Cyanation reaction & {$[41]$} & 29 & Reduction reaction & {$[56]$} \\
14 & Cyclization reaction & {$[42]$} & 30 & Ring closing synthesis & {$[57]$} \\
15 & Cyclo-addition reaction & {$[43]$} & 31 & Solvent free reaction & {$[58]$} \\
16 & Deacetylation reaction & {$[44]$} & 32 & Hydrolysis reaction & {$[59]$}
\end{tabular}

Authors apologize to the numerous scientists whose works are not cited properly, in an attempt to limit the reference list. However, asymmetric reactions, carbohydrates, $\mathrm{CO}$ insertions, condensations cyanations, heterocycle synthesis, reactions involving ionic liquids, Michael reactions, nucleoside synthesis, organometallics, benzillic acid rearrangement, Buchwald-Hartwig, Heck, Suzuki, Sonogashira, Fischer carbenes, Pauson-Khand, oxidations, peptides, proteins, photochemistry, protections/deprotections, free radicals, ring-closing metathesis (RCM), scavengers, simultaneous cooling (EMS), solid-phase (solvent free) reactions, dye synthesis, halide exchange, halogenation, macrocycles, nitration, phosgenation, polymerase chain reaction (PCR), trypsin digestion, flavones, C-alkylation, Wittig reactionetc are recognized as major success of MAOS.

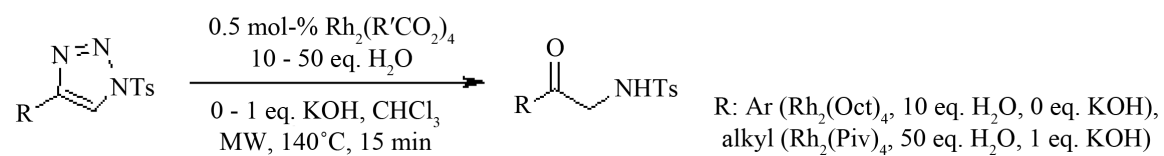

3) Various alcohols were synthesized by metal-free coupling of diazoalkanes derived from $p$-toluene sulfonylhydra zones with water under reflux and microwave conditions, in high yields [64]. In addition, this protocol was successfully applied for the synthesis of deuterium-tagged alcohols using deuterium oxide.

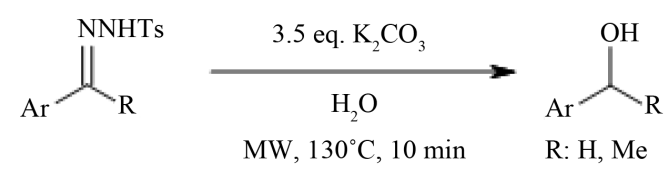

4) An efficient microwave-assisted, palladium-catalyzed hydroxylation is reported [65] that converts aryl and heteroaryl chlorides to phenols in the presence of a weak base carbonate. The reaction has shown to take place in presence of ketone, aldehyde, ester, nitrile, or amide functionalities.

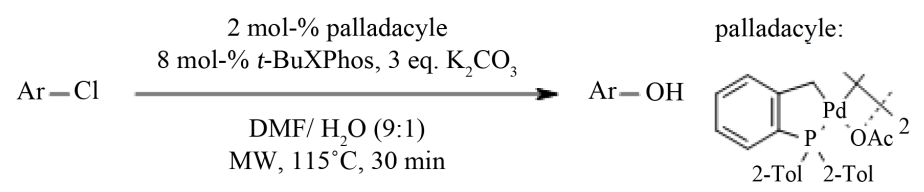

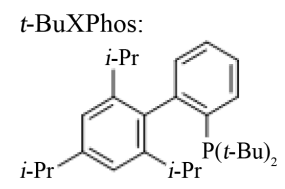


5) Microwave-irradiated condensation of carbonyl compounds with $(R)$-2-methylpropane-2-sulfinamide under solvent-free conditions in the presence of $\mathrm{Ti}(\mathrm{OEt})_{4}$ offers a simple, environmentally friendly synthesis of optically pure $N$-(tert-butylsulfinyl)imines [66]. Sulfinyl aldimines can be prepared with both excellent yields and purities in only $10 \mathrm{~min}$, while the reaction time for the preparation of ketimines has been extended to $1 \mathrm{~h}$.

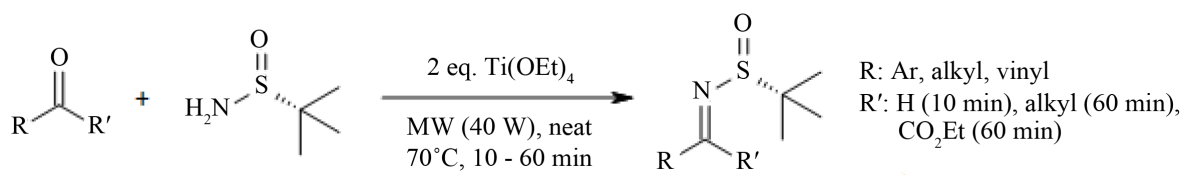

6) An efficient microwave-assisted metal-free amino benzannulation of aryl(4-aryl-1-(prop-2-ynyl)- $1 H$-imidazol-2-yl)methanone with dialkylamines affords various 2,8-diaryl-6-aminoimidazo[1,2-a]pyridines in good overall yield [67].

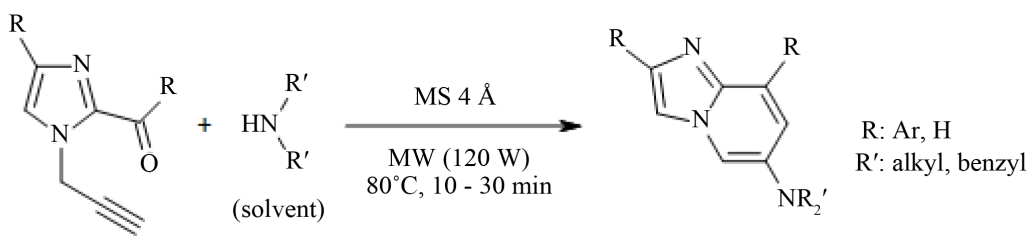

7) Sequential coupling-imination-annulation reactions of ortho-bromoarylaldehydes and terminal alkynes with ammonium acetate in the presence of a palladium catalyst under microwave irradiation furnishes different substituted isoquinolines, furopyridines and thienopyridines in good yields [68].

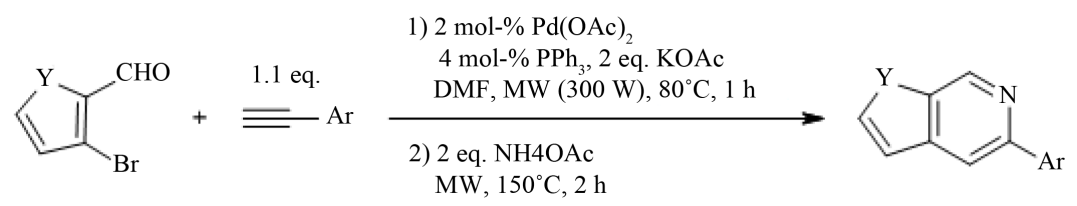

8) MW irradiation of the nitrile substrates by the Brønsted or Lewis acid catalyst has been found to be responsible for rate enhancement in azide-nitrile cycloaddition [69]. Lewis acids such as $\mathrm{Zn}$ or Al salts perform in a similar manner, activating the nitrile moiety and leading to an open-chain intermediate that subsequently cyclizes to produce the tetrazole nucleus. The desired tetrazole products were obtained in high yields within 3 - 10 min employing controlled microwave heating.

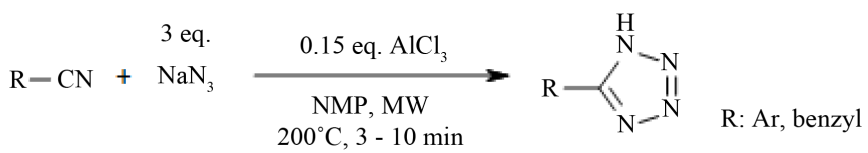

9) A multitalented microwave-assisted procedure [70] for the palladium-catalyzed direct arylation of heterocycles by aryl bromides and heteroaryl bromides using MW heating features short coupling times (10 - 60 min) and low catalyst loadings. This also allows successful arylation of previously found unreactive heterocyclic substrates.

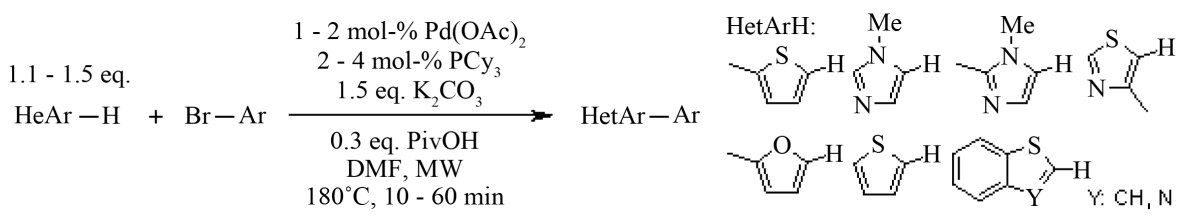

10) A comparatively easier MW assisted three-step route enabled the synthesis of arylacetaldehydes from the corresponding carboxylic acids in very high yields. A subsequent microwave-assisted Gewald reaction [71] gives 
5-substituted-2-aminothiophenes in short time, with high yields and purities.
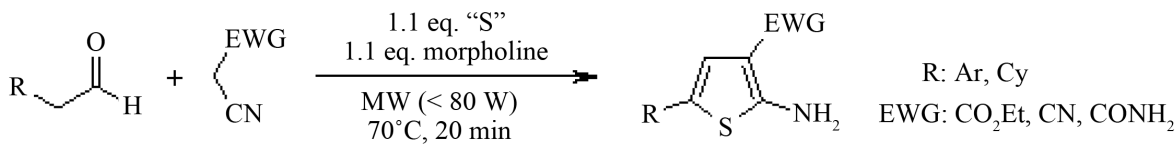

11) A straightforward and efficient $\mathrm{Yb}(\mathrm{OTf})_{3}$ catalyzed three-component reaction of aldehydes, alkynes and amines under microwave irradiation in an ionic liquid has been developed. A number of 2,4-disubstituted quinolines have been synthesized in excellent yield (69\% - 93\%) under mild reaction condition [72] and the catalyst is reused up to four times.

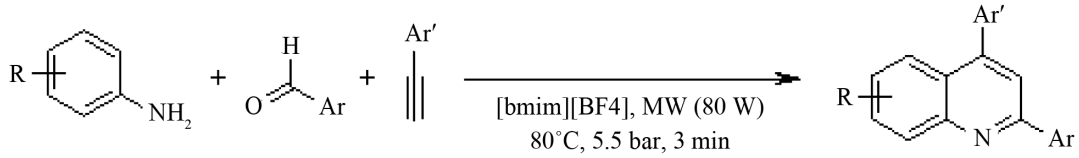

12) $3,3^{\prime}-\mathrm{Br}_{2}$-BINOL has been shown to catalyze the enantioselective asymmetric propargylation of ketones using allenyldioxoborolane as nucleophile, in absence of solvent and under microwave irradiation to afford homopropargylic alcohols in good yields (60\% - 98\%) and high enantiomeric ratios (3:1 - 99:1) [73]. Diastereoselective propargylations using chiral racemic allenylboronates result in good diastereoselectivities $(\mathrm{dr}>86: 14)$ and enantioselectivities (er > 92:8) under the catalytic conditions.

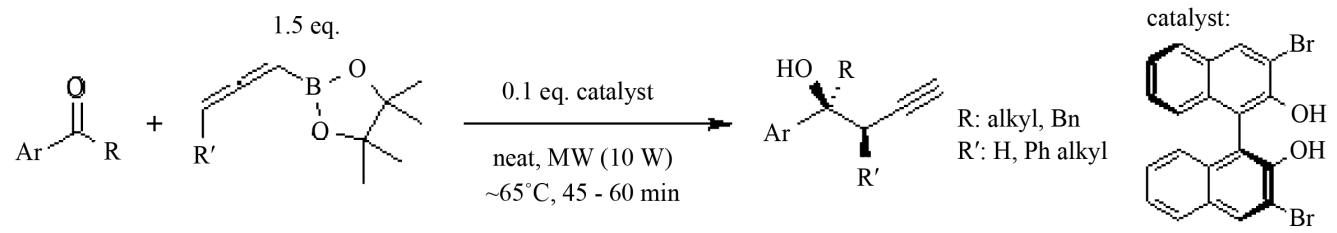

13) A facile, proficient and large-scale procedure for the synthesis of $\mathrm{N}$-(1-oxo- $1 \mathrm{H}$-inden-2-yl)benzamide derivatives via domino reaction between aryl aldehydes, hippuric acid and acetic anhydride is catalyzed by HPW/ nano- $\mathrm{SiO}_{2}$ under microwave irradiation [74]. The reaction conditions are trouble-free and offer easy isolation of the product. Moreover, the catalyst can be reused up to five times after simple filtration.
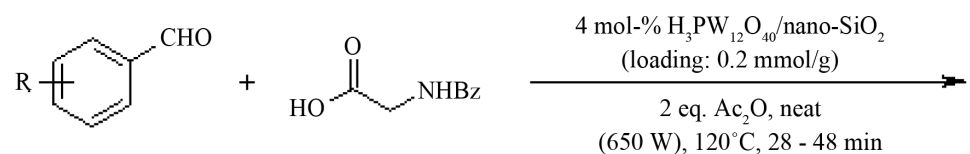<smiles>[R]c1ccc2c(c1)C=C(N[B])C2=O</smiles>

14) $\mathrm{ZrOCl}_{2} \cdot 8 \mathrm{H}_{2} \mathrm{O}$ has been identified as a highly successful, water-tolerant and reusable catalyst for the direct condensation of carboxylic acids and $N, N^{\prime}$-dimethylurea under microwave irradiation to give the corresponding $N$-methylamides in moderate to excellent yields [75]. Due to its easy availability, efficient activity, low cost and toxicity, ease of handling, easy recovery and reusability, $\mathrm{ZrOCl}_{2} \cdot 8 \mathrm{H}_{2} \mathrm{O}$ is considered as a useful green catalyst.

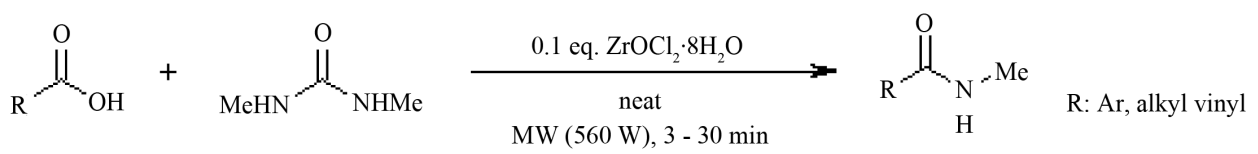

15) The efficient and simple technique for phosphine-free Heck reactions in water in the presence of Pd(Lproline $)_{2}$ complex as the catalyst under controlled microwave irradiation conditions is reported [76] to be versatile. This provides excellent yields in much short reaction times. In fact, the reaction minimizes costs, operational hazards and environmental pollution. 


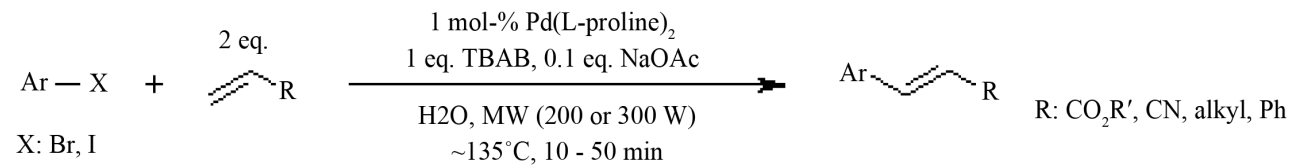

16) Aromatic nucleophilic substitutions are carried out using sodium phenoxide and 1,3,5-trichlorotriazine under microwave irradiation [77] [78].<smiles>[O-]c1ccccc1</smiles><smiles>Clc1nc(Cl)nc(Cl)n1</smiles>

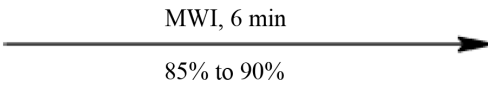

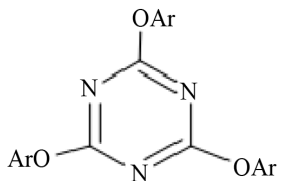

17) Under microwave irradiation a number of azaheterocycles (i.e., pyrrole, imidazole, pyrazole, indole, and carbazole) shown to react [79] remarkably fast with alkyl halides to give exclusively $N$-alkyl derivatives.

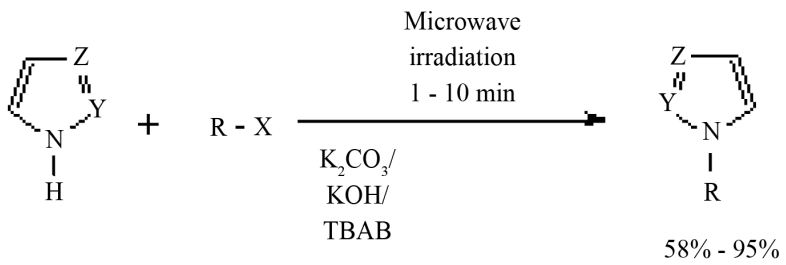

18) Condensation of acetylarenes with benzaldehydes under microwave irradiation affords [80] chalcones which undergo facile and clean cyclizations with hydrazines $\left(\mathrm{RNHNH}_{2}, \mathrm{R}=\mathrm{H}, \mathrm{Ph}, \mathrm{Ac}\right)$ to afford 3,5-arylated 2-pyrazolines in quantitative yields, also under microwave irradiation and in the presence of dry AcOH as cyclizing agent. This is actually an example of Claisen-Smith reaction under MW irradiation. The results obtained indicate that unlike classical heating, microwave irradiation results in higher yields, shorter reaction times (2 $12 \mathrm{~min}$ ) and cleaner reactions.<smiles>CC(=O)c1ccccc1</smiles><smiles>O=Cc1ccccc1</smiles>

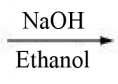<smiles>O=C(/C=C/c1ccccc1)c1ccccc1</smiles><smiles>NNc1ccccc1</smiles><smiles>CC1=NN(c2ccccc2)C(c2ccccc2)C1</smiles>

\subsection{Advantages of Microwave Chemistry [81]}

Microwave radiation has proved to be a highly effective heating source in chemical reactions. Microwaves can speed up the reaction rate, afford better yields and uniform as well as selective heating, achieve better reproducibility of reactions and help in improving cleaner and greener synthetic pathways.

Increased Rate of Reactions [82]: Compared to conventional heating, microwave heating enhances the rate of certain chemical reactions by 10 to 1000 times. This is due to its ability to considerably augment the temperature of a reaction, for instance, synthesis of fluorescein, which usually takes about 10 hours by conventional heating methods, can be conducted in only 35 minutes by means of microwave heating (Table 5).

Efficient Source of Heating [83]-[85]: Heating by means of microwave radiation is a highly resourceful process and results insignificant energy savings. This is primarily because microwaves heat up just the sample and not the apparatus and therefore, energy consumption is less. A typical example is the use of microwave radiation in the ashing process. Since microwave ashing devices can reach temperatures of over $800^{\circ} \mathrm{C}$ in $\sim 50 \mathrm{mi}-$ nutes, they eliminate the lengthy heating-up periods associated with conventional electrical-resistance furnaces. This drastically lowers the associated energy costs. 
Table 5. Comparison of reaction duration (in minutes).

\begin{tabular}{ccc}
\hline Reaction & Conventional & Microwave \\
\hline Synthesis of Fluorescein & 600 & 35 \\
Condentation of Benzoin with Urea & 60 & 8 \\
Biginelli Reaction & 360 & 35 \\
Synthesis of Aspirin & 130 & 1 \\
Synthesis of Phenothiazine & 60 & 4 \\
\hline
\end{tabular}

Higher Yields [86]: In certain chemical reactions, microwave radiation produces higher yields compared to conventional heating methods, for example, microwave synthesis of fluorescein results in an increase in the yield of the reaction, from $70 \%$ to $82 \%$ (Table 6 ).

Uniform Heating: Microwave radiation, unlike conventional heating methods, provides uniform heating throughout a reaction mixture.

Selective Heating: Selective heating is based on the principle that different materials respond differently to microwaves. Some materials are transparent whereas others absorb microwaves. Therefore, microwaves can be used to heat a combination of such materials.

Environmentally-Friendly Chemistry [87]: Reactions performed in microwaves are reasonably cleaner and more environmentally friendly than conventional heating methods. Microwaves heat the compounds directly therefore, usage of solvents in the chemical reaction can be reduced or eliminated.

Greater Reproducibility of Chemical Reactions: Reactions with microwave heating are more reproducible compared to conventional heating because of uniform heating and better control of process parameters.

\section{Question of Greenness: A Comment}

Assessment of "greenness" of microwave assisted transformations is a relatively complex job that demands consideration of different factors into account. The issue of the energy efficiency of microwave vs. conventionally heated reactions must, in general, be estimated with great care on a case-by-case basis. However, as a number of studies have demonstrated, it should be emphasized that the microwave heating process performed in laboratoryscale single-mode microwave reactors is sufficiently energy inefficient [88]. As the irresistible bulk of the more than 5000 published microwave chemistry experiments rely on the use of this type of equipment, it is highly questionable whether this non-classical form of heating should be labeled as being green, sustainable or environmentally friendly, based on energy efficiency considerations. However, when moving from laboratory scale to kilogram scale and from single-mode to multimode reactors, microwave heating processes can indeed be more energy efficient than conventionally heated experiments, assuming otherwise conditions remain identical. This has been highlighted in a number of recent studies derived from different laboratories [88].

\section{Limitations of Microwave Chemistry [83] [84]}

The limitations of microwave chemistry are linked to its scalability, limited application, and the hazards involved in its use.

Lack of Scalability: The product obtained by using microwave apparatus available in the market is restricted to a few grams. Though there has been improvement in the recent past, relating to the scalability [87] of microwave apparatus, there is still a space that needs to be linked to make the machinery scalable. This is principally true for reactions at the industrial level and for solid-state reactions.

Limited Applicability: The use of microwaves as a heating source has restricted applicability for materials that absorb them. Microwaves cannot heat materials such as sulphur, which are transparent to their radiation. In addition, although microwave heating increases the rate of reaction in certain reactions, it also results in yield reduction compared to conventional heating methods [89].

Safety Hazards Related to the Use of Microwave-Heating Apparatus: Even though makers of microwaveheating apparatus have directed their research to make microwaves a secure source of heating, uncontrolled reaction involving volatile reactants under superheated conditions may result with explosions. Furthermore, in- 
Table 6. Comparison of yields (\%).

\begin{tabular}{ccc}
\hline Reaction & Conventional & Microwave \\
\hline Synthesis of Fluorescein & 70 & 82 \\
Condentation of Benzoin with Urea & 70 & 73 \\
Biginelli Reaction & 70 & 75 \\
Synthesis of Aspirin & 85 & 92 \\
Synthesis of Phenothiazine & 71 & 86
\end{tabular}

appropriate use of microwave heating for rate enhancement of chemical reactions involving radioisotopes may result in uncontrolled and harmful radioactive decay. Certain evils, with dangerous end results, have also been observed while conducting polar acid-based reactions, e.g., microwave irradiation of are action involving concentrated sulphuric acid may spoil the polymer vessel used for heating. This is because sulphuric acid is a strong coupler of microwave energy and raises the reaction temperature to $300^{\circ} \mathrm{C}$ within a very short time. As a result, the polymer microwave-heating container may melt, with hazardous consequences [90]. Conducting microwave reactions at high-pressure conditions may also result in uncontrolled reactions and cause explosions.

Health Risk Related to the Use of Microwave-heating Apparatus: Health hazards in connection with microwaves are caused by the penetration of microwaves. When microwaves operating at a low frequency range are only able to penetrate the human skin, higher frequency-range microwaves have been found to reach body organs. Studies have proven [91] that on extended exposure to microwaves may result in the complete degeneration of body tissues and cells. It has also been established that constant exposure of DNA to high-frequency microwaves during a biochemical reaction may lead to complete degeneration of the DNA strands. Research has been carried out to understand this phenomenon and two schools of thoughts have evolved. The first is based on the thermal degeneration of DNA by microwave irradiation and believes that microwaves have enough energy to disrupt the covalent bond of a DNA strand. The other discipline of thought is emphatic about the existence of a "non-thermal microwave effect". Kakita et al. [92] [93] have shown that in identical thermal conditions, microwave irradiated DNA strands are different from those heated under conventional heating methods. Microwave irradiated DNA strands were habitually damaged which does not occur in conventional heating. This discovery has restricted the use of microwave heating to only biological reactions.

Other limitations:

- Sudden increase in temperature may lead to the distortion of molecular structures which may lead to rapture of them and may yield undesired products [94].

- MAOS reactions are generally short-timed, so, always a care must be taken during the process [95].

- Temperature sensitive reactions, reactions involving bumping of materials or reactions which involve effervescences are ordinarily difficult to perform in Microwave reactors [96].

- Since heating takes place too fast, sometimes reactions become vigorous and to some extent hazardous [96].

- Dedicated or focused microwave reactors are generally expensive and therefore, special care must be taken during and after their use [96].

\section{Future Prospect and Conclusions}

As with almost all instances of incorporation of new technology in an industrial set up, the question remains: Is it being employed to the level of maximum extent possible? At the present time, microwave-assisted organic synthesis is no longer a curiosity but a promising technology whose full latent possibility has yet not been explored. The use of microwave ovens to heat reactions is a paradigm shift for nearly all trained synthetic chemists. In reality, the use of microwaves as an energy source requires a mind-set change in the way in which synthetic chemistry is practised. Initial use requires conversion of traditional reaction conditions to microwave conditions. Household MW ovens create not only sudden untoward incidents but also affect the quality of publications [22]. Even though, most MAOS reactions are unfortunately still performed in domestic household ovens. If truth be told, for example, the use of $70 \%$ of full power for 5 minutes in a domestic microwave oven will never be a quantitative measurement of the energy delivered to a reaction [22]. Hence, novel, dedicated and refined MW reactors with ability to reproduce performance and minimal hazard should be used rather than the domestic counter-top variants. New 
development in MW reactors and vessel designing are required with respect to scale-up, high throughput and more reliable temperature control. In future, with discovery of new MW assisted reactions, suitable technologies will also be developed to carry out these reactions on industrial scales. In concert with rapidly expanding application possibilities, microwave synthesis can be effectively applied to any category of synthetic chemistry, resulting in faster reaction times and improved product yields.

At present, the benefits of microwaves as a source of energy for heating chemical reactions are adequately clear. What is less clear, as with most innovative techniques or technologies, is what is the rate of uptake of this approach and what factors are affecting the implementation rate. Though the percentage of reactions being performed with microwave irradiation has not been quantified appropriately, the use of microwave energy to promote a diverse range of chemistry is continuously escalating. It is interesting to note that the country in which the technique seems to be most accepted, according to the number of publications, is India [22]. This illustrates that the MAOS reactions possess enormous potential to be a very sturdy tactical tool for advancement of basic sciences even in the financially disadvantageous regions of the globe. With the rapidly expanding number of published examples and the readily available tips and tools that accompany commercial instrumentation, the leap from traditional heating to microwave heating is far less disappointing than when the field began. Despite several limitations and restrictions, use of microwave heating in MAOS chemistry will continue to grow and is likely to become a standard procedure in coming years.

\section{References}

[1] Gedye, R., Smith, F., Westaway, K., Ali, H., Baldisera, L., Laberge, L. and Rousell, J. (1986) The Use of Microwave Ovens for Rapid Organic Synthesis. Tetrahedron Letters, 27, 279-282. http://dx.doi.org/10.1016/S0040-4039(00)83996-9

[2] Giguere, R.J., Bray, T.L. and Duncan, S.M. (1986) Application of Commercial Microwave Oven to Organic Synthesis. Tetrahedron Letters, 27, 4945-4948. http://dx.doi.org/10.1016/S0040-4039(00)85103-5

[3] Jin, Q.H. (1999) Microwave Chemistry. Science Press, Beijing.

[4] Kappe, C.O. (2004) Controlled Microwave Heating in Modern Organic Synthesis. Angewandte Chemie International Edition, 43, 6250-6284. http://dx.doi.org/10.1002/anie.200400655

[5] (a) Pradhan, D.K., Dharamrajan, T.S., Mishra, M.R. and Mishra, A. (2012) An Overview of Microwave Oven in the Field of Synthetic Chemistry. International Journal of Research and Development in Pharmacy \& Life Sciences (IJRDPL), 44, 44-50.

(b) Taylor, M., Atri, S.S. and Minhas, S. Evalueserve Analysis: Developments in Microwave Chemistry. www.rsc.org/images/evalueserve_tcm18-16758.pdf

(c) Horeis, A.G., Pichler, S., Stadler, A., Gössler, W. and Kappe, C.O. (2001) Microwave-Assisted Organic Synthesis-Back to the Roots. 5th International Electronic Conference on Synthetic Organic Chemistry (ECSOC-5), Basel, 1-30 September 2001. http://www.mdpi.org/ecsoc-5.htm

[6] http://shodhganga.inflibnet.ac.in/bitstream/10603/3197/8/08_chapter\%201.pdf

[7] The type of radiation emitted by MW ovens is non-ionizing. This means that unlike X-ray or UV light, it does not have potential to cause cancer. Although it possess possible heat-burn risks. Dr. Spencer himself, despite being literally surrounded by intense microwaves for a long period of his life, lived to the ripe old age of 76, dying apparently of natural causes.

(a) Stuerga, D. and Delmotte, M. (2002) Chapter 1. Wave-Material Interactions, Microwave Technology and Equipment. In: Loupy, A., Ed., Microwaves in Organic Synthesis, Wiley-VCH, Weinheim, 1-34.

(b) Mingos, M.D.P. (2004) In: Lidstrom, P. and Tierney, J.P., Eds., Microwave-Assisted Organic Synthesis, Blackwell, Oxford.

(c) Gabriel, C., Gabriel, S., Grant, E.H., Halstead, B.S. and Mingos, D.M.P. (1998) Dielectric Parameters Relevant to Microwave Dielectric Heating. Chemical Society Reviews, 27, 213-223.

(d) Kerr, J.A. (1992) Strengths of Chemical Bonds. In: Lide, D.R., Ed., CRC Handbook of Chemistry and Physics, 76th Edition, CRC Press, Boca Raton, Ann Arbor, London, Tokyo, 51.

(e) Atkins, P.W. (1990) Physical Chemistry. Oxford University Press, Oxford, 938.

(f) Stuerga, D.A.C. and Gaillard, P. (1996) Microwave Athermal Effects in Chemistry: A Myth’s Autopsy Part I: Historical Background and Fundamentals of Wave-Matter Interaction. The Journal of Microwave Power Electromagnetic Energy, 31, 87-100.

[8] In specific cases, magnetic field interactions have also been observed, see:

(a) Stass, D.V., Woodward, J.R., Timmel, C.R., Hore, P.J. and McLauchlan, K.A. (2000) Radiofrequency Magnetic Field Effects on Chemical Reaction Yields. Chemical Physics Letters, 329, 15-22. 
http://dx.doi.org/10.1016/S0009-2614(00)00980-5

(b) Timmel, C.R. and Hore, P.J. (1996) Oscillating Magnetic Field Effects on the Yields of Radical Pair Reactions. Chemical Physics Letters, 257, 401-408. http://dx.doi.org/10.1016/0009-2614(96)00466-6

(c) Woodward, J.R., Jackson, R.J., Timmel, C.R., Hore, P.J. and McLauchlan, K.A. (1997) Resonant Radiofrequency Magnetic Field Effects on a Chemical Reaction. Chemical Physics Letters, 272, 376-382. http://dx.doi.org/10.1016/S0009-2614(97)00542-3

[9] Hayes, B.L. (2002) Microwave Synthesis: Chemistry at the Speed of Light. CEM Publishing, Matthews NC and References Cited Therein.

[10] Gaba, M. and Dhingra, N. (2011) Microwave Chemistry: General Features and Applications. Indian Journal of Pharmaceutical Education and Research, 45, 175-183.

[11] http://www.milestonesci.com

[12] http://www.maos.net

[13] http://www.cem.com

[14] Westaway, K.C. and Gedye, R.J. (1995) The Question of Specific Activation of Organic Reactions by Microwaves. Journal of Microwave Power and Electromagnetic Energy, 30, 219-230.

[15] Kuhnert, N. (2002) Microwave-Assisted Reactions in Organic Synthesis-Are There Any Nonthermal Microwave Effects? Angewandte Chemie International Edition, 41, 1863-1866. http://dx.doi.org/10.1002/1521-3773(20020603)41:11<1863::AID-ANIE1863>3.0.CO;2-L

[16] Langa, F., De la Cruz, P., De la Hoz, A., Diaz-Ortiz, A. and Diez-Barra, E. (1997) Microwave Irradiation: More than Just a Method for Accelerating Reactions. Contemporary Organic Synthesis, 4, 373-386. http://dx.doi.org/10.1039/co9970400373

[17] Saillard, R., Poux, M., Berlan, J. and Audhvy-Peaudecert, M. (1995) Microwave Heating of Organic Solvents: Thermal Effects and Field Modeling. Tetrahedron, 51, 4033-4042. http://dx.doi.org/10.1016/0040-4020(95)00144-W

[18] Stuerga, D. and Gaillard, P. (1996) Microwave Heating as a New Way to Induce Localized Enhancements of Reaction Rate. Non-Isothermal and Heterogeneous Kinetics. Tetrahedron, 52, 5505-5510. http://dx.doi.org/10.1016/0040-4020(96)00241-4

[19] Caddick, S. (1995) Microwave Assisted Organic Reactions. Tetrahedron, 51, 10403-10432. http://dx.doi.org/10.1016/0040-4020(95)00662-R

[20] Strauss, C.R. and Trainor, R.W. (1995) Developments in Microwave-Assisted Organic Chemistry. Australian Journal of Chemistry, 48, 1665-1692. http://dx.doi.org/10.1071/CH9951665

[21] Bose, A.K., Banik, B.K., Lavlinskaia, N., Jayaraman, M. and Manhas, M.S. (1997) MORE Chemistry in a Microwave. Chemtech, 27, 18-124.

[22] Lidstrom, P., Tierney, J., Wathey, B. and Westman, J. (2001) Microwave Assisted Organic Synthesis—A Review. Tetrahedron, 57, 9225-9283. http://dx.doi.org/10.1016/S0040-4020(01)00906-1

[23] Nuchter, M., Ondruschka, B. and Lautenschlager, W. (2003) Microwave-Assisted Chemical Reactions. Chemical Engineering \& Technology, 26, 1208-1216. http://dx.doi.org/10.1002/ceat.200301836

[24] Nuchter, M., Ondruschka, B., Bonrath, W. and Gum, A. (2004) Microwave Assisted Synthesis-A Critical Technology Overview. Green Chemistry, 6, 128-141. http://dx.doi.org/10.1039/b310502d

[25] Abramovitch, R.A. (1991) Applications of Microwave Energy in Organic Chemistry. A Review. Organic Preparations and Procedures International, 23, 683-711. http://dx.doi.org/10.1080/00304949109458244

[26] Leadbeater, N.E. (2010) In Situ Reaction Monitoring Of Microwave-Mediated Reactions Using IR Spectroscopy. Chemical Communications, 46, 6693-6695. http://dx.doi.org/10.1039/c0cc01921f

[27] (a)http://www.mrl.ucsb.edu/polymer-characterization-facility/instruments/microwave-reactor-biotage (b)http://www.biotagepathfinder.com/pressurePC.jsp

[28] For recent reviews on microwave-assisted organic synthesis see:

(a) Adam, D. (2003) Microwave Chemistry: Out of the Kitchen. Nature, 421, 571-572. http://dx.doi.org/10.1038/421571a

(b) Kappe, C.O. and Dallinger, D. (2006) The Impact of Microwave Synthesis on Drug Discovery. Nature Reviews Drug Discovery, 5, 51-63. http://dx.doi.org/10.1038/nrd1926

(c) Nagariya, A.K., Meena, A.K., Kiran, K., Yadav, A.K., Niranjan, U.S., Pathak, A.K., Singh, B. and Rao, M.M. (2010) Microwave Assisted Organic Reaction as New Tool in Organic Synthesis. Journal of Pharmacy Research, 3, 575-580.

(d) Jignasa, K.S., Ketan, T.S., Bhumika, S.P. and Anuradha, K.G. (2010) Microwave Assisted Organic Synthesis: An Alternative Synthetic Strategy. Der Pharma Chemica, 2, 342-353. 
(e) Bose, A.K., Banik, B.K., Lavlinskaia, N., Jayaraman, M. and Manhas, M.S. (1997) MORE Chemistry in a Microwave. Chemtech, 27, 18-24.

(f) Bose, A.K., Manhas, M.S., Ganguly, S.N., Sharma, A.H. and Banik, B.K. (2002) MORE Chemistry for Less Pollution: Applications for Process Development. Synthesis, 11, 1578-1591. http://dx.doi.org/10.1055/s-2002-33344

[29] Moghaddam, F.M. and Sharifi, A. (1995) Microwave Promoted Acetalization of Aldehydes and Ketones. Synthetic Communications, 25, 2457-2461. http://dx.doi.org/10.1080/00397919508015450

[30] Mogilaiah, K., Kavita, S. and Babu, H.R. (2003) Microwave Assisted Addition-Elimination Reactions of 3-Phenylimino2-Indolinones with 2-Hydrazino-3-(p-Chlorophenyl)-1, 8-Naphthyridine: A Simple and Facile Synthesis of 3-(3-p-Chlorophenyl-1,8-Naphthyridin-2-yl Hydrazono)-2-Indolinones. Indian Journal of Chemistry, 42B, 1750-1752.

[31] Abramovitch, R.A., Shi, Q. and Bogdal, D. (1995) Microwave-Assisted Alkylations of Activated Methylene Groups. Synthetic Communications, 25, 1-8. http://dx.doi.org/10.1080/00397919508010781

[32] Miljanic, O.S., Volhardt, K.P.C. and Whitener, G.D. (2003) An Alkyne Metathesis-Based Route to ortho-Dehydrobenzannulenes. Synlett, 1, 29-34.

[33] Motorina, I.A., Parly, F. and Grierson, D.S. (1996) Selective O-Allylation of Amidoalcohols on Solid Support. Synlett, 4, 389-391. http://dx.doi.org/10.1055/s-1996-5416

[34] Mccarroll, A.J., Sandham, D.A., Titumb, L.R., Dek Lewis, A.K., Cloke, F.G.N., Davies, B.P., Desantand, A.P., Hiller, W. and Caddicks, S. (2003) Studies on High-Temperature Amination Reactions of Aromatic Chlorides Using Discrete Palladium-N-Heterocyclic Carbene (NHC) Complexes and in Situ Palladium/Imidazolium Salt Protocols. Molecular Diversity, 7, 115-123. http://dx.doi.org/10.1023/B:MODI.0000006863.14423.da

[35] Angrish, C., Kumar, A. and Chouhan, S.M.S. (2005) Microwave Assisted Aromatic Nucleophilic Substitution Reaction of Chloronitrobenzenes with Amines in Ionic Liquids. Indian Journal of Chemistry, 44B, 1515-1518.

[36] Ermolat'ev, D.S., Giménez, V.N., Babaev, E.V. and Van der Eycken, E. (2006) Efficient Pd(0)-Mediated MicrowaveAssisted Arylation of 2-Substituted Imidazo[1,2-a]Pyrimidines. Journal of Combinatorial Chemistry, 8, 659-663.

[37] Azarifar, D. and Ghasemnejad, H. (2003) Microwave-Assisted Synthesis of Some 3,5-Arylated-2-Pyrazolines. Molecules, 8, 642-648. http://dx.doi.org/10.3390/80800642

[38] Al-Obeidi, F., Austin, R.E., Okonoya, J.F. and Bond, D.R.S. (2003) Microwave-Assisted Solid-Phase Synthesis (MASS): Parallel and Combinatorial Chemical Library Synthesis. Mini-Reviews in Medicinal Chemistry, 3, 449-460. http://dx.doi.org/10.2174/1389557033488042

[39] Kim, J.K., Kwon, P.S., Kwon, T.W., Chung, S.K. and Lee, J.W. (1996) Application of Microwave Irradiation Techniques for the Knoevenagel Condensation. Synthetic Communications, 26, 535-542. http://dx.doi.org/10.1080/00397919608003646

[40] Burten, G., Cao, P., Li, G. and Rivero, R. (2003) Palladium-Catalyzed Intermolecular Coupling of Aryl Chlorides and Sulfonamides under Microwave Irradiation. Organic Letters, 5, 4373-4376. http://dx.doi.org/10.1021/ol035655u

[41] Arevela, R.K. and Leadbeater, N.E. (2003) Rapid, Easy Cyanation of Aryl Bromides and Chlorides Using Nickel Salts in Conjunction with Microwave Promotion. Journal of Organic Chemistry, 68, 9122-9125. http://dx.doi.org/10.1021/jo0350561

[42] Crawford, K.R., Bur, S.K., Straub, C.S. and Padwa, A. (2003) Intramolecular Cyclization Reactions of 5-Halo- and 5-Nitro-Substituted Furans. Organic Letters, 5, 3337-3340. http://dx.doi.org/10.1021/ol035233k

[43] Lerestif, J.M., Perocheav, J., Tonnard, F., Bazareav, J.P. and Hamelin, J. (1995) 1,3-Dipolar Cycloaddition of Imidate Ylides on Imino-Alcohols: Synthesis of New Imidazolones Using Solvent Free Conditions. Tetrahedron, 51, 67576774. http://dx.doi.org/10.1016/0040-4020(95)00321-X

[44] Jayakumar, G., Ajithabai, M.D., Santhosh, B., Veena, C.S. and Nair, M.S. (2003) Microwave Assisted Acetylation and Deacetylation Studies on the Triterpenes Isolated from Dysoxylum malabaricum and Dysoxylum beddomei. Indian Journal of Chemistry, 42B, 429-431.

[45] Calinescu, I., Calinescu, R., Martin, D.I. and Radoiv, M.T. (2003) Microwave-Enhanced Dechlorination of Chlorobenzene. Research on Chemical Intermediates, 29, 71-81. http://dx.doi.org/10.1163/156856703321328424

[46] Mavoral, J.A., Cativicla, C., Garcia, J.I., Pires, E., Rovo, A.J. and Figueras, F. (1995) Diels-Alder Reactions of $\alpha$-Amino Acid Precursors by Heterogeneous Catalysis: Thermal vs. Microwave Activation. Applied Catalysis A, 131, 159-166. http://dx.doi.org/10.1016/0926-860X(95)00131-X

[47] Santagoda, V., Fiorino, F., Perissuti, E., Severino, B., Terracciano, S., Cirino, G. and Caliendo, G. (2003) A Convenient Strategy Of Dimerization By Microwave Heating And Using 2,5-Diketopiperazine As Scaffold. Tetrahedron Letters, 44, 1145-1148.

[48] Mazo, P.C. and Ríos, L.A. (2010) Esterification and Transesterification Assisted by Microwaves of Crude Palm Oil: 
Homogeneous Catalysis. Latin American Applied Research, 40, 343-349.

[49] Diaz-Ortiz, A., De la Hoz, A., Merrero, M.A., Prieto, P., Sanchez-Migallon, A., Cassio, F.P., Arriela, A., Vivanco, S. and Foces, C. (2003) Enhancing Stereochemical Diversity by Means of Microwave Irradiation in the Absence of Solvent: Synthesis of Highly Substituted Nitroproline Esters via 1,3-Dipolar Reactions. Molecular Diversity, 7, 175-180. http://dx.doi.org/10.1023/B:MODI.0000006799.01924.2e

[50] Jnagaki, T., Fukuhara, T. and Hara, S. (2003) Effective Fluorination Reaction with $\mathrm{Et}_{3} \mathrm{~N} .3 \mathrm{HF}$ under Microwave Irradiation. Synthesis, 8, 1157-1159.

[51] Lechmann, F., Pilotti, A. and Luthman, K. (2003) Efficient Large Scale Microwave Assisted Mannich Reactions Using Substituted Acetophenones. Molecular Diversity, 7, 145-152. http://dx.doi.org/10.1023/B:MODI.0000006809.48284.ed

[52] Kiasat, A.R., Kazemi, F. and Rafati, M. (2003) Microwave Promoted Rapid Oxidation of Alcohols Using Cobalt Nitrate Hexahydrate Supported on Silica Gel Under Solvent Free Conditions. Synthetic Communications, 33, 601-605. http://dx.doi.org/10.1081/SCC-120015814

[53] Gospondinova, M., Gredard, A., Jeannin, M., Chitanv, G.C., Carpov, A., Thiery, V. and Besson, T. (2002) Efficient Solvent-Free Microwave Phosphorylation of Microcrystalline Cellulose. Green Chemistry, 4, 220-222. http://dx.doi.org/10.1039/b200295g

[54] Vu, Z.T., Liu, L.J. and Zhuo, R.X. (2003) Microwave-Improved Polymerization of $\epsilon$-Caprolactone Initiated by Carboxylic Acids. Journal of Polymer Science Part A: Polymer Chemistry, 41, 13-21. http://dx.doi.org/10.1002/pola.10546

[55] Srikrishana, A. and Kumar, P.P. (1995) Naphthalenes Microwave Irradiation Induced Rearrangement on Montmorillonite K-10. Tetrahedron Letters, 36, 6313-6316. http://dx.doi.org/10.1016/0040-4039(95)01219-8

[56] Danks, T.N. and Wagner, G. (2005) Microwave-Assisted Reductions. In: Tierney, J.P. and Lidström, P., Eds., Microwave Assisted Organic Synthesis, Blackwell Publishing Ltd., Oxford. http://dx.doi.org/10.1002/9781444305548.ch4

[57] Garbacia, S., Desai, B., Lavastre, O. and Kappe, C.O. (2003) Microwave-Assisted Ring-Closing Metathesis Revisited. On the Question of the Nonthermal Microwave Effect. Journal of Organic Chemistry, 68, 9136-9139. http://dx.doi.org/10.1021/jo035135c

[58] Laurent, A., Jacquault, P., Di Martino, J.L. and Hamelin, J. (1995) Fast Synthesis of Amino Acid Salts and Lactams without Solvent under Microwave Irradiation. Chem. Commun., 11, 1101.

[59] Nielsen, T.E. and Schreiber, S.L. (2007) Towards the Optimal Screening Collection: A Synthesis Strategy. Angewandte Chemie International Edition, 47, 48-56. http://dx.doi.org/10.1002/anie.200703073

[60] (a) Hayes, B.L. (2004) Recent Advances in Microwave-Assisted Synthesis. Aldrichimica Acta, 37, 66-76. (b) Bogdal, D. (2005) Microwave-Assisted Organic Synthesis: One Hundred Reaction Procedures (Tetrahedron Organic Chemistry). Elsevier Science, Amsterdam.

[61] (a) Seijas, J.A., Vázquez-Tato, M.P. and Carballido-Reboredo, R. (2005) Solvent-Free Synthesis of Functionalized Flavones under Microwave Irradiation. Journal of Organic Chemistry, 70, 2855-2858.

(b) Ranu, B.C., Guchhait, S.K., Ghosh, K. and Patra, A. (2000) Construction of Bicyclo[2.2.2]octanone Systems by Microwave-Assisted Solid Phase Michael Addition Followed by $\mathrm{Al}_{2} \mathrm{O}_{3}$-Mediated Intramolecular Aldolisation. An Eco-Friendly Approach. Green Chemistry, 2, 5-6. http://dx.doi.org/10.1039/a907689a

[62] Porcheddu, A., Mura, M.G., De Luca, L., Pizzetti, M. and Taddei, M. (2012) From Alcohols to Indoles: A Tandem Ru Catalyzed Hydrogen-Transfer Fischer Indole Synthesis. Organic Letters, 14, 6112-6115. http://dx.doi.org/10.1021/ol3030956

[63] Miura, T., Biyajima, T., Fujii, T. and Murakami, M. (2012) Synthesis of $\alpha$-Amino Ketones from Terminal Alkynes via Rhodium-Catalyzed Denitrogenative Hydration of N-Sulfonyl-1,2,3-Triazoles. Journal of the American Chemical Society, 134, 194-196. http://dx.doi.org/10.1021/ja2104203

[64] García-Muñoz, Á., Ortega-Arizmendi, A.I., García-Carrillo, M.A., Díaz, E., Gonzalez-Rivas, N. and Cuevas-Yañez, E. (2012) Direct, Metal-Free Synthesis of Benzyl Alcohols and Deuterated Benzyl Alcohols from $p$-Toluenesulfonylhydrazones Using Water as Solvent. Synthesis, 44, 2237-2242. http://dx.doi.org/10.1055/s-0031-1290372

[65] Yu, C.W., Chen, G.S., Huang, C.W. and Chern, J.W. (2012) Efficient Microwave-Assisted Pd-Catalyzed Hydroxylation of Aryl Chlorides in the Presence of Carbonate. Organic Letters, 14, 3688-3691. http://dx.doi.org/10.1021/ol301523q

[66] Collados, J.F., Toledano, E., Guijarro, D. and Yus, M. (2012) Microwave-Assisted Solvent-Free Synthesis of Enantiomerically Pure $N$-(Tert-Butylsulfinyl)Imines. Journal of Organic Chemistry, 77, 5744-5750. http://dx.doi.org/10.1021/jo300919x

[67] Nagaraj, M., Boominathan, M., Muthusubramanian, S. and Bhuvanesh, N. (2012) Microwave-Assisted Metal-Free Synthesis of 2,8-Diaryl-6-Aminoimidazo-[1,2-a]Pyridine via Amine-Triggered Benzannulation. Synlett, 23, $1353-1357$. 
http://dx.doi.org/10.1055/s-0031-1290979

[68] Yang, D., Burugupalli, S., Daniel, D. and Chen, Y. (2012) Microwave-Assisted One-Pot Synthesis of Isoquinolines, Furopyridines, and Thienopyridines by Palladium-Catalyzed Sequential Coupling-Imination-Annulation of 2-Bromoarylaldehydes with Terminal Acetylenes and Ammonium Acetate. Journal of Organic Chemistry, 77, 4466-4472. http://dx.doi.org/10.1021/jo300494a

[69] Cantillo, D., Gutmann, B. and Kappe, C.O. (2011) Mechanistic Insights on Azide-Nitrile Cycloadditions: On the Dialkyltin Oxide-Trimethylsilyl Azide Route and a New Vilsmeier-Haack-Type Organocatalyst. Journal of the American Chemical Society, 133, 4465-4475. http://dx.doi.org/10.1021/ja109700b

[70] Baghbanzadeh, M., Pilger, C. and Kappe, C.O. (2011) Palladium-Catalyzed Direct Arylation of Heteroaromatic Compounds: Improved Conditions Utilizing Controlled Microwave Heating. Journal of Organic Chemistry, 76, 8138-8142. http://dx.doi.org/10.1021/jo201516v

[71] Revelant, G., Dunand, S., Hesse, S. and Kirsch, G. (2011) Microwave-Assisted Synthesis of 5-Substituted 2-Aminothiophenes Starting from Arylacetaldehydes. Synthesis, 2011, 2935-2940.

[72] Kumar, A. and Rao, V.K. (2011) Microwave-Assisted and Yb(OTf)3-Promoted One-Pot Multicomponent Synthesis of Substituted Quinolines in Ionic Liquid. Synlett, 15, 2157-2162. http://dx.doi.org/10.1055/s-0030-1261200

[73] Barnett, D.S. and Schaus, S.E. (2011) Asymmetric Propargylation of Ketones Using Allenylboronates Catalyzed by Chiral Biphenols. Organic Letters, 13, 4020-4023. http://dx.doi.org/10.1021/ol201535b

[74] Rostami, M., Khosropour, A.R., Mirkhani, V., Mohammadpoor-Baltork, I., Moghadam, M. and Tangestaninejad, S. (2011) An Efficient, Simple, and Scaleable Domino Reaction to Diverse $N$-(1-Oxo- $1 H$-inden-2-yl)benzamides Catalyzed by HPW at Nano-SiO ${ }_{2}$ under Microwave Irradiation. Synlett, 2011, 1677-1682.

[75] Talukdar, D., Saikia, L. and Thakur, A.J. (2011) Zirconyl Chloride: An Efficient, Water-Tolerant, and Reusable Catalyst for the Synthesis of N-Methylamides. Synlett, 11, 1597-1601.

[76] Allam, B.K. and Singh, K.N. (2011) An Efficient Phosphine-Free Heck Reaction in Water Using Pd(L-Proline $)_{2}$ as the Catalyst Under Microwave Irradiation. Synthesis, 2011, 1125-1131.

[77] Seijas, J.A., Vazquez-Tato, M.P., Martinez, M.M. and Corredoira, G.N. (1999) Direct Synthesis of Imides from Dicarboxylic Acids Using Microwaves. Journal of Chemical Research, 1999, 420-425.

[78] Dahmani, Z., Rahmouni, M., Brugidou, R., Bazureau, J.P. and Hamelin, J. (1998) A New Route to $\alpha$-Hetero $\beta$-Enamino Esters Using a Mild and Convenient Solvent-Free Process Assisted by Focused Microwave Irradiation. Tetrahedron Letters, 39, 8453-8456. http://dx.doi.org/10.1016/S0040-4039(98)01894-2

[79] Bogdal, D., Pielichowski, J. and Jaskot, K. (1997) Remarkable Fast N-Alkylation of Azaheterocycles under Microwave Irradiation in Dry Media. HeteroCycles, 45, 715-722. http://dx.doi.org/10.3987/COM-96-7731

[80] Azarifar, D. and Ghasemnejad, H. (2003) Microwave-Assisted Synthesis of Some 3,5-Arylated 2-Pyrazolines. Molecules, 8, 642-648. http://dx.doi.org/10.3390/80800642

[81] Michael, C.J. and Dennis, M.P. (1988) Microwave Heating Apparatus for Laboratory Analyses. CEM Corporation. US Patent No. 4835354.

[82] Price, W.H. and Earl, E.K. (1999) Pressure Vessel with Composite Sleeve. CEM Limited, L.L.C. US Patent No. 6534140.

[83] Bernd, O., et al. (2002) Device for Performing Safety Functions in Areas with High Frequency Radiation. Mikrowellen-Labor-SystemeGmbh. US Patent No. 20020096340A1.

[84] Edward, J.T., Price, W.H. and Earl Edward, K. (1999) Pressure Sensing Reaction Vessel for Microwave Assisted Chemistry. CEM Corporation. US Patent No. 6124582.

[85] Price, W.H. (1999) Sealing Closure for High-Pressure Vessels in Microwave Assisted Chemistry. CEM Corporation. US Patent No. 6287526.

[86] Stone-Elander, S. and Elander, N. (2002) Microwave Applications in Radiolabelling with Short-Lived Positron-Emitting Radionuclides. Journal of Labelled Compounds and Radiopharmaceuticals, 45, 715-746. http://dx.doi.org/10.1002/jlcr.593

[87] Stadler, A., Yousefi, B.H., Dallinger, D., Walla, P., Van der Eycken, E., Kaval, N. and Kappe, C.O. (2003) Scalability of Microwave-Assisted Organic Synthesis. From Single-Mode to Multimode Parallel Batch from Single-Mode to Multimode Parallel Batch Reactors. Organic Process Research Development, 7, 707-716.

[88] Moseley, J.D. and Kappe, C.O. (2011) A Critical Assessment of the Greenness and Energy Efficiency of MicrowaveAssisted Organic Synthesis. Green Chemistry, 13, 794-806. http://dx.doi.org/10.1039/c0gc00823k

[89] MILESTONES Inc. (2014) Digestion. http://www.milestonesci.com/digestion.php

[90] MILESTONES Inc. (2014) Extraction. http://www.milestonesci.com/extraction.php 
[91] Developments in Microwave Chemistry (2005) Royal Society of Chemistry, Evalueserve, London, UK.

[92] Kakita, Y., Kashige, N., Murata, K., Kuroiwa, A., Funatsu, M. and Watanabe, K. (1995) Inactivation of Lactobacillus Bacteriophage PL-1 by Microwave Irradiation. Microbiology and Immunology, 39, 571-576. http://dx.doi.org/10.1111/j.1348-0421.1995.tb02244.X

[93] Kakita, Y., Funatso, M., Miake, F. and Watanabe, K. (1999) Effects of Microwave Irradiation on Bacteria Attached to the Hospiral White Coats. International Journal of Occupational Medicine and Environmental Health, 12, $123-126$.

[94] Sekhon, B.S. (2010) Microwave-Assisted Pharmaceutical Synthesis: An Overview. International Journal of PharmTech Research, 2, 827-833.

[95] Nüchter, M., Ondruschka, B., Bonrath, W. and Gum, A. (2004) Microwave Assisted Synthesis-A Critical Technology Overview. Green Chemistry, 6, 128-141.

[96] Brett, A. and Christopher, R. (2005) Toward Rapid, “Green”, Predictable Microwave-Assisted Synthesis. Accounts of Chemical Research, 38, 653-661. http://dx.doi.org/10.1021/ar040278m 